\title{
E-Learning in Postsecondary Education
}

\author{
Bradford S. Bell and Jessica E. Federman
}

\section{Summary}

Over the past decade postsecondary education has been moving increasingly from the classroom to online. During the fall 2010 term 31 percent of U.S. college students took at least one online course. The primary reasons for the growth of e-learning in the nation's colleges and universities include the desire of those institutions to generate new revenue streams, improve access, and offer students greater scheduling flexibility. Yet the growth of e-learning has been accompanied by a continuing debate about its effectiveness and by the recognition that a number of barriers impede its widespread adoption in higher education.

Through an extensive research review, Bradford Bell and Jessica Federman examine three key issues in the growing use of e-learning in postsecondary education. The first is whether e-learning is as effective as other delivery methods. The debate about the effectiveness of e-learning, the authors say, has been framed in terms of how it compares with other means of delivering instruction, most often traditional instructor-led classroom instruction. Bell and Federman review a number of meta-analyses and other studies that, taken together, show that e-learning produces outcomes equivalent to other delivery media when instructional conditions are held constant. The second issue is what particular features of e-learning influence its effectiveness. Here the authors move beyond the "does it work" question to examine how different instructional features and supports, such as immersion and interactivity, influence the effectiveness of e-learning programs. They review research that shows how these features can be configured to create e-learning programs that help different types of learners acquire different types of knowledge. In addressing the third issue-the barriers to the adoption of e-learning in postsecondary education-Bell and Federman discuss how concerns about fraud and cheating, uncertainties about the cost of e-learning, and the unique challenges faced by low-income and disadvantaged students have the potential to undermine the adoption of e-learning instruction.

Based on their research review, the authors conclude that e-learning can be an effective means of delivering postsecondary education. They also urge researchers to examine how different aspects of these programs influence their effectiveness and to address the numerous barriers to the adoption of online instruction in higher education.

www.futureofchildren.org

Bradford S. Bell is an associate professor of human resource studies and director of executive education in the ILR School at Cornell University. Jessica E. Federman is a Ph.D. student in human resource studies in the ILR School at Cornell University. 


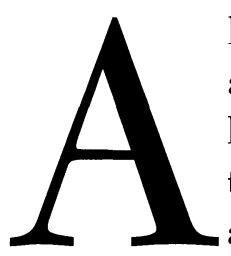
lthough most student training and development in U.S. colleges and universities continues to take place with teachers and students interacting faceto-face in traditional classrooms, the past decade has witnessed a significant migration of postsecondary education from the classroom to online. A 2011 Babson Survey Research Group poll of more than 2,500 chief academic officers found that 65 percent view online learning as a critical part of their long-term strategy. ${ }^{1}$ The survey also revealed that more than 6 million, or 31 percent, of the nation's college students took at least one online course during the fall 2010 term, an increase of more than 560,000 , or 10.1 percent, over the previous year. Although this figure is significantly lower than the 21.1 percent annual growth in online enrollment recorded by Babson in fall 2009, it far exceeds the 0.6 percent annual growth in the overall number of higher education students during the same period.

The growth of e-learning in postsecondary education is not limited to online courses and programs but rather covers an expanding array of applications and approaches that use technology in different ways and to varying degrees. These applications include simple videotaped lectures posted on the Internet, as well as learning-management systems, such as Blackboard, that distribute content such as lecture notes, syllabi, and assignments and facilitate peer and student-teacher interaction. They also include more sophisticated online collaborative simulations that create highfidelity learning environments and interactive e-learning systems that use artificial intelligence to deliver customized instruction to students. ${ }^{2}$ Interest is also growing in making learning accessible to students through mobile devices, such as smartphones and tablets.
There are a variety of reasons for the growth of e-learning in postsecondary institutions, including a need to generate new revenue streams, expand access, offer students greater scheduling flexibility and the freedom to work at their own pace, and curb increasing costs. As e-learning has been expanding, however, so have debates about its effectiveness and concerns about its impact on the quality of higher education. According to Babson, for example, although two-thirds of the academic leaders polled believe that online education is just as good as or better than face-to-face instruction, the remaining one-third believe the learning outcomes of online courses are inferior to those of faceto-face instruction. ${ }^{3}$ As might be expected, leaders at institutions that do not offer online courses or programs tend to be more skeptical. A survey of the general public conducted by the Pew Research Center using a nationally representative sample of 2,142 adults found that only 29 percent believe online courses are as valuable educationally as courses taken in the classroom. ${ }^{4}$

In this article we address three key questions about the growth of e-learning in postsecondary education. First, is e-learning as effective as other delivery media? The debate about the effectiveness of e-learning has typically been framed in terms of how it compares with other means of delivering instruction, particularly traditional teacher-led classroom instruction. To examine this question we review research that evaluates the effectiveness of e-learning by comparing learning outcomes across different delivery media. Second, what features of e-learning influence its effectiveness? Exploring this issue requires moving beyond the "does it work" question to a more nuanced consideration of the conditions under which e-learning is likely to be most effective in postsecondary settings. Third and 
finally, what are the barriers to the adoption of e-learning in higher education? Before addressing these questions, we define and describe e-learning and review current trends in how it is being used in higher education.

\section{What Is E-Learning?}

For researchers, e-learning is a vast and somewhat disconnected area of inquiry that has attracted interest from disciplines as diverse as educational psychology, computer science, information science, management, communications, and more. The breadth of the subject and the divergent objectives among those studying e-learning have led to a fragmented understanding of what e-learning means and how it should be defined. The current state of affairs is perhaps best illustrated by the many terms used to refer to instruction delivered through computer technology-e-learning, online learning, distance learning, distance education, computer-assisted instruction, computer-based instruction, technology-based instruction, technology-delivered instruction, computer-based simulation, and simulation games. In their recent review of e-learning research, Kenneth Brown, Steven Charlier, and Abigail Pierotti identified forty-six distinct terms. ${ }^{5}$ One explanation for this proliferation of terms is that the seemingly endless combinations and variants of technologies create different e-learning applications with very different capabilities. Another is the constantly evolving nature of e-learning, with new terms accompanying the introduction of new e-learning technologies or applications. Further complicating matters, e-learning can be used either as a stand-alone delivery tool or as a supplement to face-to-face instruction (the latter commonly known as "hybrid" or "blended” learning). As William Bowen and several colleagues suggest, “'online learning' is hardly one thing. It comes in a dizzying variety of flavors."6
The challenge for those seeking to make sense of this field is that these terms are often applied inconsistently. For example, the terms "e-learning" and "online learning" are frequently used to refer to instruction in which most (often 80 percent or more) of the content is delivered through networked technology (such as the Internet), although the same terms have also been used to refer to programs delivered through nonnetworked digital technologies (for example, CD or DVD). Further, some analysts distinguish between specific delivery media, such as "online learning," and broad approaches to instruction, such as "distance education," whereas others use these terms interchangeably. Such inconsistent use of terms can make it difficult to determine the equivalency of courses or programs examined across studies. Accordingly, our view is that it matters less what specific label or term analysts use for a particular learning program than that they provide clear and detailed information about the technological and instructional features embedded in it. That is, it is important for investigators to describe the defining features of the e-learning programs they examine so findings across different studies can be appropriately aggregated and compared. In reality, however, authors commonly neglect to report important details about the learning technologies and learner experiences they examine.

We use the umbrella term "e-learning" to refer to all forms of electronically supported instruction. In their review, Brown, Charlier, and Pierotti formally define "e-learning" as "a broad array of applications and processes that share a common feature of relying on some type of computer technology to promote learning." 7 That expansive definition fits nicely with our own objective, which is to provide a broad review of technology in 
postsecondary education. Another feature common to most postsecondary e-learning is that it relies on the Internet. ${ }^{8}$ As noted, the term "e-learning," along with "online learning" and "web-based instruction," usually refers to instruction delivered through network technology. Finally, we use the term "e-learning" because it is commonly used among the general public, as well as by colleges when they refer to their technologyenabled courses or degree programs. For example, a Google search yields about 94 million results for "e-learning," compared with 33 million for "distance learning" and 20 million for "online learning." Although we use this broad term throughout the article, we are careful to note when particular findings or conclusions are confined to a specific type of technology.

\section{Current Trends in Postsecondary E-Learning}

Institutions of higher education are putting much thought into how they might optimize their course enrollment and attract new students by delivering instruction through e-learning applications. Among the most active participants in the college e-learning market are large state systems such as the University of Maryland University College (UMUC), Pennsylvania State University, and the University of Massachusetts

(UMassOnLine). In 2011, more than 70,000 students worldwide enrolled in at least one online UMUC course and the university had more than 230,000 enrollments in onlineonly courses. UMUC, which has been educating students in Europe since 1949 and in Asia since 1956, claims to be the largest four-year public university in the United States and the largest public provider of higher education to working professionals and to U.S. military personnel and their family members.
For-profit universities are also a growing part of the online college market. The University of Phoenix (UP), which describes itself as the largest private university in North America, enrolled more than 380,000 students in degree programs in 2011. In its more than 100 degree programs at the associate's through the doctoral level, students can attend class online, in a traditional classroom, or a combination of both. Its 2011 Annual Academic Report noted that 2.2 percent of its students are nonresident aliens, 18.4 percent are black, 36.3 percent are white, and 68.9 percent are female. More than half of the graduate student body consists of minority students..$^{9}$ As of September 2010, Kaplan University offered ninety-six academic programs, including fifty-nine degree programs (associate's, bachelor's, and graduate), two diploma programs, thirty-two certificate programs, and three law-related degrees through distance, blended online, and oncampus learning. According to Kaplan's 2010 annual report, of the more than 68,000 students enrolled during 2009-10, 75 percent were women and 55 percent were over the age of thirty. ${ }^{10}$ Other prominent for-profit institutions include Laureate International Universities, which enrolls students from more than 120 countries in bachelor's, master's, and doctoral programs, and Strayer University, which offers associate's, bachelor's, and master's degrees in a variety of areas, including business administration, accounting, and information technology. The article by David Deming, Claudia Goldin, and Lawrence Katz in this issue examines forprofit colleges in detail. ${ }^{11}$

Over the past decade, the number of students enrolling in e-learning courses at these and other postsecondary institutions has grown dramatically. The National Center for Education Statistics estimates that between 
2000 and 2008 the share of undergraduates enrolled in at least one online course grew from 8 percent to 20 percent. ${ }^{12}$ As noted, the Babson Survey Research Group estimated that by the fall of 2010,31 percent of all higher education students were taking at least one online course. ${ }^{13}$ Further, Babson estimated that between 2002 and 2010 online enrollments grew at a rate of 18.3 percent, compared with just more than 2 percent for the overall postsecondary education student body. A 2011 Pew Research Center survey of more than 1,000 U.S. colleges and universities found that 82 percent of community colleges offer online courses, compared with 79 percent of research universities and 61 percent of liberal arts colleges. ${ }^{14}$ It also found that 91 percent of two-year colleges offered online classes, compared with 89 percent of four-year public colleges and universities and 60 percent of private colleges and universities.

\section{The National Center for}

Education Statistics estimates that between 2000 and 2008 the share of undergraduates enrolled in at least one online course grew from 8 percent to 20 percent.

According to a 2011 survey conducted by the Instructional Technology Council, the share of students taking online classes at community colleges is split almost equally between traditional students aged eighteen through twenty-five (48 percent) and nontraditional students twenty-six and over (47 percent). ${ }^{15}$
Some 62 percent of online students are female; 37 percent, male. Although online courses and degrees are offered in a wide array of subject areas, the online-only bachelor's degree major that enrolls the most students is criminal justice. As estimated by the firm Eduventures, 27 percent of all online-only enrollments are in criminal justice, followed by 19 percent in computer and information technology, 16 percent in health care, and 14 percent in business. ${ }^{16}$ Online enrollments are estimated to be growing most rapidly in fields related to health care. ${ }^{17}$

\section{Is E-Learning as Effective as Other Delivery Media?}

Even as online enrollment continues to grow, concerns remain about the legitimacy and value of e-learning in postsecondary education. The debate about the effectiveness of e-learning has historically been cast in terms of how electronic delivery of instruction compares with other forms of delivery, particularly traditional classroom delivery, which remains the most common form of instruction in higher education. For reasons we discuss later, we do not find studies comparing the effectiveness of different media terribly enlightening. But because this comparison has attracted significant attention not only from academics but also from administrators and the general public, we next provide an overview of academic and public perspectives on the comparative effectiveness of e-learning and other delivery media. We then review empirical evidence on effectiveness and discuss its implications for e-learning in postsecondary settings.

\section{Academic and Public Perspectives on the Effectiveness of E-Learning}

Among researchers, views on the relative effectiveness of e-learning and traditional instruction fall into two primary camps. 
Richard Clark has argued that there is nothing uniquely advantageous to any delivery medium and that, therefore, a well-designed media comparison study should find no effects. ${ }^{18}$ Clark sees technology as a mere tool to be manipulated at the hands of instructional design, pedagogical approaches, and teacher practices. As he puts it, "media only deliver instruction but do not influence learning." ${ }^{19}$ In the same vein, Steven Ross, Gary Morrison, and Deborah Lowther contend that "educational technology is not a homogeneous ‘intervention' but a broad variety of modalities, tools, and strategies for learning. Its effectiveness, therefore, depends on how well it helps teachers and students achieve the desired instructional goals." ${ }^{20}$ In sum, according to this view, e-learning should be no more or less effective than any other form of instructional delivery. As with other types of instruction, e-learning's effectiveness depends on how well it is designed to create the instructional experience that makes learning possible.

Academic advocates of e-learning, by contrast, cite numerous potential pedagogical benefits, such as customizing instruction to the learner, creating multimedia (text, images, sound, video) information environments, and increasing interactivity. ${ }^{21}$ Because many media tools today have moved beyond simple prerecorded videos and can now offer more interaction between learners and teachers, among learners, and between the learner and the content, some observers argue that different delivery media can offer unique learning support. They contend that in certain situations e-learning can lead to better academic outcomes by creating an instructional experience that is difficult or impossible to create in the classroom or through alternative media.
A third perspective on the effectiveness of e-learning, more prevalent among the general public than among academics, is that the outcomes associated with e-learning courses are inferior to those of traditional, face-toface instruction. William Bowen and his co-authors cite "concerns that at least some kinds of online learning are low quality and that online learning in general de-personalizes education." ${ }^{22}$ As noted, the Pew Research Center reports that a majority of the general public, including young adults who have grown up in a digital world, believes that online courses offer less educational value than traditional classroom courses. ${ }^{23}$ Lawrence Bacow and several colleagues also note that many faculty are skeptical of the value of e-learning because it differs from the way in which they were taught and because they fear it will distance them from their students, thereby undermining the educational and mentoring process. ${ }^{24}$

\section{Empirical Evidence on Effectiveness}

Over the past several decades, thousands of studies have examined the effectiveness of e-learning, broadly defined. Much of this work has compared e-learning with traditional classroom instruction and other forms of delivery media. Early research focused primarily on evaluating distance education, such as televised broadcasts and videoconferencing, but over time attention shifted to computer-based instruction and most recently to online instruction as well as computer-based simulations. Proponents of this research argue that a systematic account explaining why and how learning effectiveness differs between different forms of delivery could help policy makers, administrators, researchers, and educational-design specialists determine the equivalency and value of ongoing innovation. ${ }^{25}$ 
Over the years, however, e-learning research has been hamstrung by several important methodological limitations. Although these deficiencies are sometimes beyond the control of investigators, they have nonetheless led to questions about the validity of the research findings. ${ }^{26}$ For example, many studies have used what is called "single group pretest, post-test designs," which can lead to an upward bias in effect sizes. ${ }^{27}$ And even in more sophisticated two-group study designs that compare treatment groups with comparison, or control, groups, participants are often not randomly assigned to treatment and control conditions (only in the gold standard, or experimental, study designs are participants assigned randomly). Participants may thus self-select into different instructional conditions, which can allow preexisting differences among them to go unmeasured and lead to bias in observed effects. As a second illustration of methodological limits, some studies, even those with comparison groups, can confound differences in delivery media with differences in instruction. ${ }^{28}$ In other words, the instruction received by participants in the e-learning condition is often not equivalent to that received by participants in the classroom or comparison condition. In certain forms of e-learning, such as simulations, for example, students may be required to engage more actively than they would in a classroom environment. Because instructional methods that facilitate active engagement enhance learning, differences in achievement may be attributable to differences in activity level rather than in the delivery media per se. ${ }^{29}$ The curriculum materials and the time spent in learning can also differ across the e-learning and comparison groups, thus leading to differences in achievement. In short, because differences in delivery media are often associated with differences in other instructional features, studies that contrast different delivery media are often not making apples-to-apples comparisons.

A comprehensive review of this vast and diverse research literature is beyond the scope of this article. Instead, we focus on several meta-analyses that have been conducted on e-learning research. Meta-analysis is a technique for combining the results of multiple studies to obtain an overall estimate of a particular effect or relationship. One of the advantages of meta-analysis is that by aggregating the findings of multiple studies it reduces the influence of factors that are idiosyncratic to a specific study. In addition, the meta-analyses that we examine acknowledge the methodological limitations noted above and take steps to try to address them. For example, all of the meta-analyses screened studies to ensure they met a basic level of methodological rigor, such as employing if not an experimental design, at least a quasiexperimental design, in which there is a comparison group that receives a comparable treatment and often an attempt to statistically control for differences between the students engaged in e-learning and those engaged in other forms of learning. Studies that did not meet these minimum standards were excluded from the meta-analyses. Furthermore, each of the meta-analyses recorded methodological and substantive differences across studies, such as whether the curriculum and instruction was equivalent in the treatment and comparison conditions, and examined these differences to see whether they affected the results. Despite these efforts, the studies included in the meta-analyses vary significantly in terms of methodology. And because many studies provide limited information about the nature of instruction in different conditions, it is impossible to account fully for potentially important instructional differences that may 
be influencing the findings. For example, in their meta-analysis, Robert Bernard and his co-authors note that the studies of e-learning they reviewed commonly describe thoroughly the e-learning condition, but offer little detail about the comparison condition (classroom instruction). ${ }^{30}$

These limitations notwithstanding, we believe the meta-analyses provide the most comprehensive assessment of the effectiveness of e-learning relative to other delivery media. We next review the findings of several metaanalyses, emphasizing more recent reviews because they often incorporate studies analyzed in earlier reviews and are also more likely to include studies that examine the effectiveness of modern forms of e-learning such as web-based learning and interactive simulations. In addition, we devote attention to reviews that focus primarily on adult learners because those findings are more likely to generalize to college students.

\section{Results of Meta-Analysis}

The meta-analysis conducted by Bernard and his colleagues examined 232 studies (yielding 688 effect sizes) dated from 1985 to 2002 that compared e-learning (which they termed distance education) with traditional, or classroom, instruction on measures of achievement, student attitude, and course completion. ${ }^{31}$ The studies focused on two types of e-learning - asynchronous (mostly correspondence and online courses, in which students participate at different times) and synchronous (mostly teleconferencing and satellite-based delivery, in which all students participate simultaneously)—and included a mixed population of students, including $\mathrm{K}-12$, graduate, and military, although most were undergraduates. Measures of student achievement showed no significant overall difference between e-learning and classroom instruction. Measures of student attitude showed a small but significant difference, with students generally favoring classroom instruction over e-learning, although they rated only synchronous e-learning significantly lower than they rated classroom instruction. Course completion measures showed a very small but significant overall difference in favor of classroom instruction, though only when compared with asynchronous e-learning. In summary, the meta-analysis revealed no significant overall difference between e-learning and traditional instruction in terms of overall achievement, but more negative student attitudes toward synchronous e-learning and higher dropout rates in asynchronous e-learning.

\section{Measures of student attitude showed a small but significant difference, with students generally favoring classroom instruction over e-learning, although they rated only synchronous e-learning significantly lower than they rated classroom instruction.}

A meta-analysis by Traci Sitzmann and several colleagues compared the effectiveness of classroom and web-based instruction, defined as a "hypermedia-based instructional program, which utilizes the attributes and resources of the World Wide Web to create a meaningful learning environment where learning is fostered and supported." ${ }^{32}$ Their 
analysis of ninety-six published and unpublished studies involving 19,331 students found that web-based instruction was 6 percent more effective than traditional classroom instruction for teaching declarative knowledge (facts and principles), but not procedural knowledge (rules and procedures) or student reactions. Used as a supplement to classroom instruction (blended learning), web-based instruction was 13 percent more effective than classroom instruction for declarative knowledge and 20 percent more effective for procedural knowledge. These findings, however, should be interpreted with caution because offering web-based instruction as a supplement may lead to more learning time or other important instructional differences relative to the comparison classroom condition. Indeed, the authors found web-based and classroom instruction equally effective for teaching declarative knowledge when the instructional methods used in both were equivalent. They attribute the small overall advantage of web-based instruction to its use of more (and more effective) instructional methods, rather than to the delivery media per se.

Another recent meta-analysis, conducted by the U.S. Department of Education, Office of Planning, Evaluation, and Policy Development, examined fifty independent effect sizes from forty-five studies evaluating online learning. ${ }^{33}$ Although the metaanalysis was designed to draw conclusions about online learning in the context of K-12 education, only five studies with K-12 students met the inclusion criteria set by the authors. The remaining studies focused on college undergraduates or those in graduate programs or professional training. The findings revealed that students who took a course online did not perform significantly differently than those taking the same course through traditional face-to-face instruction. Students in courses that combined online and face-to-face instruction (blended learning) had stronger learning outcomes than did those in face-to-face instruction alone. Both instructor-directed and collaborative and interactive online instruction (both fully online and blended) led to stronger outcomes than classroom instruction, but outcomes in independent online learning and face-to-face instruction had no significant difference. Finally, the positive effect of online learning (both fully online and blended) was reduced somewhat when curriculum materials and instructional approach were equivalent across conditions.

In a study published in 2011, Sitzmann used meta-analytic techniques to examine the instructional effectiveness of computer-based simulation games. ${ }^{34}$ The studies that she analyzed used different kinds of comparison groups, with participants in some receiving no training and those in others receiving alternative instructional methods. To be included in the meta-analysis, a study had to focus on adult learners (aged eighteen or older) and on training that facilitated potentially job-relevant knowledge or skills. The analysis, which covered a total of sixty-five independent samples from fifty-five reports, revealed that trainees in the simulation game group had 11 percent higher declarative knowledge, 14 percent higher procedural knowledge, 9 percent higher retention, and 20 percent higher self-efficacy than trainees in the comparison group. The entertainment value of the simulation did not influence its effectiveness, nor did differences in methodology across studies (for example, studies with and without random assignment). Results did vary, however, by the type of instruction provided to the comparison group and the simulation group. Simulation games were 
more effective than lectures, assignments, and readings, but less effective than computerized tutorials. Trainees learned more from simulation games when they had unlimited access to the games (presumably leading to more time spent learning) and when the games were embedded in a program of instruction (blended learning). In fact, when simulation games were the sole instructional method, trainees in the comparison group learned more than those in the simulation game group. Finally, in studies that matched the simulation and comparison groups in terms of the activity level of instruction, learning was similar across conditions. Once again, this finding suggests that the learners in the simulation games condition may have been advantaged not because of the delivery media per se, but rather because they often received more active instruction than those in the comparison group.

\section{Effectiveness of E-Learning: Conclusions}

These meta-analytic studies paint a rather complex picture of the effectiveness of e-learning. Overall their findings, as well as the findings of earlier reviews not discussed here, suggest that e-learning is at least as effective as, and in some cases more effective than, classroom instruction. But taking into account various methodological and instructional factors can change the findings - typically not reversing them but rather weakening or eliminating the observed benefits of e-learning. Furthermore, some of the meta-analyses found widely varying effect sizes for the relationship between e-learning and the learning outcomes, with some studies finding e-learning much more effective than classroom instruction and others finding it much less effective. Such variability suggests that other explanations - such as aspects of the instruction, teacher effectiveness, or student characteristics-account for the relative effectiveness of e-learning in the studies.

Several recent studies that have attempted to address the deficiencies of earlier work in this area have provided a more rigorous evaluation of the effect of e-learning on student achievement. David Figlio, Mark Rush, and Lu Yin, for example, randomly assigned students in a large introductory microeconomics course to either live lectures or online delivery of the recorded lectures. ${ }^{35}$ The sections differed only in the method of delivery and were identical in all other ways, including the instruction, assignments, and teaching assistant support. Overall, the course exam scores for students in the live instruction and online sections showed no significant difference, although certain students-specifically, Hispanic students, males, and low achievers-performed significantly better in the live instruction section. In a study already noted, William Bowen and his co-authors randomly assigned students in an introductory statistics course conducted at six public universities to either a traditional classroom-based section or a hybrid section. ${ }^{36}$ In the hybrid section, most of the instruction was delivered through interactive online materials, but students also attended for one hour a week a face-to-face session where they could ask questions and receive assistance. Student learning outcomes in the traditional and hybrid sections showed no statistically significant difference. Nor did outcomes differ across subgroups - whether by race and ethnicity, gender, or college grade point average-indicating that no subgroups of students consistently benefited from or were harmed by the hybrid format. The rigorous design of both of these studies made possible a precise estimate of the differences (or lack thereof) between conditions. As a result, though both reached the same conclusion 
as the meta-analyses - that e-learning is, on average, as effective as traditional classroom instruction-their use of random assignment and strong controls engenders more confidence in their findings.

So, what can we ultimately conclude from the multitude of studies comparing the effectiveness of e-learning and other forms of instruction? The current body of evidence appears to support the position asserted by Richard Clark more than two decades ago: pedagogy, not delivery media, is what influences learning. Or as Terry Anderson observes, "It seems clear that there is no single medium that supports the educational experience in a manner that is superior in all ways to that supported via other media." ${ }^{37}$ Rather, characteristics of the instructional design, such as the instructional methods used, the feedback provided, and the degree of learner engagement, create the conditions within which learning occurs. The meta-analyses reviewed above show that when instructional design characteristics are held constant across delivery conditions, e-learning and classroom instruction generally produce similar learning outcomes. That finding suggests that delivery media themselves do not affect learning, but rather are simply the vehicles through which instructional conditions are delivered to the learner. Furthermore, the finding suggests that studies designed to evaluate the effectiveness of a particular e-learning technology are of limited value. Indeed, any form of instruction can be effective if it is able to create the conditions necessary for students to learn specific content. As Brown, Charlier, and Pierotti conclude in their review of e-learning, "we could study whether people learn using iPods with no screen, iPods with a small screen, e-readers (e.g., Nooks, Kindles) with blackand-white or color screens, iPads (which have a larger color screen), and <insert future technology here $>$. Invariably, the answer to the question will be, yes, people can learn using these media" (italics in original). ${ }^{38}$ Similarly, studies that simply compare different media, without considering differences in instructional methodology or learning environments, do not provide an accurate picture of the effectiveness of one type of media relative to another. Ultimately, research needs to move beyond the "does it work" question toward a better understanding of exactly what does influence the effectiveness of e-learning and thus of the conditions under which e-learning is likely to be most effective.

\section{What Features of E-Learning Influence Its Effectiveness?}

Researchers have now begun to investigate the effectiveness of e-learning by evaluating not the different technologies themselves but rather the effects of specific instructional features and supports embedded in them. Several authors have developed conceptual frameworks or typologies of e-learning to help guide such efforts. Steve Kozlowski and Bradford Bell, for example, present a typology that highlights four key categories of instructional features-content, immersion, interactivity, and communication-by which e-learning technologies can create a specific instructional experience. ${ }^{39}$ By content they mean the level of richness with which information is delivered to learners. Text, for example, is low in information richness, whereas images, sound, and video are high. Kozlowski and Bell use the term immersion to denote the sense of realism that e-learning can create-the extent to which the learning experience captures the psychological and physical characteristics of a performance. Certain forms of technology, for example, such as simulations, offer greater possibilities for enhancing learners' sense of being immersed in the educational experience. 
The term interactivity refers to characteristics that influence the degree and type of interaction between learners (individually or as groups), between learners and instructors, and, increasingly, between learners and simulated characters or virtual agents. Networked forms of e-learning, for example, have expanded the potential for collaboration and interactivity. The final feature, communication richness or bandwidth, determines students' ability to communicate verbally and nonverbally. E-learning programs differ in the extent to which they make available different communication channels (for example, audio and video) and allow students to communicate synchronously in real time. Kozlowski and Bell stress that the importance of different features depends on the goals of a particular learning program and the instructional environment that must be created to meet the needs of learners. That is, no configuration of features will be universally effective or ineffective. Rather, effectiveness is determined by the degree of fit between the design of the e-learning and the characteristics of the course for which it is used. Educators can use research of this sort-work that focuses on how different technological configurations can deliver specific instructional features - to guide decisions about which type of e-learning should be used to meet specific learning objectives.

Other conceptual work has focused on isolating specific instructional features of e-learning. Interactivity has received particular attention. In a review of computer games and simulations, Jennifer Vogel and several colleagues argue that interactivity is the key instructional component that influences learning outcomes. ${ }^{40}$ In 1989, Michael Moore identified three forms of interaction in distance education: student-student interaction, student-instructor interaction, and student-content interaction. ${ }^{41}$ Drawing on Moore's typology, Terry Anderson proposed that e-learning can support meaningful learning as long as at least one form of interaction is at a high level. ${ }^{42}$ High levels of multiple forms of interaction may enhance the educational experience, but may make it less cost- or time-effective. What Anderson calls his "equivalency theorem"-that one type of interactivity can substitute for the others with little loss in educational effectivenessfurther delineates the different forms of interactivity and shows how different technologies can meet learner needs through different types of interactivity. Future research must directly test the equivalency theorem to learn whether specific types of interaction are better suited than others to meet specific learner needs and instructional objectives.

Empirical research is also shifting away from evaluating whether e-learning works and toward examining the instructional features that influence its effectiveness. Rather than comparing different forms of delivery such as e-learning versus classroom, studies are beginning to compare e-learning programs that differ on important instructional dimensions, including interactivity, engagement and activity, and feedback. Richard Mayer, for example, has conducted research on multimedia learning to better understand how people learn in such environments and to identify which aspects of those environments can help different types of learners acquire different kinds of knowledge. ${ }^{43}$ Robert Bernard and several coauthors have conducted a meta-analysis to examine how different types of interaction influence the effectiveness of e-learning programs, which they call distance education. ${ }^{44}$ Based on seventy-four effect sizes drawn from seventyfour studies, they found that programs offering moderate to high levels of interaction 
had better achievement outcomes than those offering less interaction. They found, interestingly, that programs that incorporated student-student or student-content interaction led to better achievement than those offering student-teacher interaction. They also found that increasing the degree of interaction led to better achievement in the case of studentcontent interaction, but not student-student or student-instructor interaction. To repeat, the effects of a certain type of interaction will depend on how well it matches the content and objectives of a particular course. Yet, as this meta-analysis shows, on average, interactivity significantly influences the effectiveness of e-learning programs, and certain types of interaction may lead to better outcomes than others.

In summary, research provides evidence that e-learning can effectively deliver instruction in postsecondary settings. As with any delivery media, whether a particular e-learning program is effective in a given situation will depend on its capacity to create the conditions necessary for students to learn. The key challenges now facing college administrators and faculty are to decide when to use e-learning and how to design and deliver it to maximize student achievement. As yet, however, e-learning research provides minimal guidance on these central questions. In other areas, such as the organizational training literature, researchers have mapped the effectiveness of specific training design features, such as lecture, self-instruction, or discussion, as a function of the skill or task being taught. ${ }^{45}$ Such research can guide decisions about what methods should be used to teach different skills or tasks. As noted, similar research evaluating the effectiveness of e-learning features such as interactivity and immersion for teaching different content would help curriculum planners decide when e-learning is appropriate and what type of e-learning should be used to deliver the features critical to learning in a particular course or program.

\section{Barriers to E-Learning in Postsecondary Education}

Observers have pointed to a number of potential obstacles to e-learning instruction in higher education. ${ }^{46}$ In this final section we examine several emerging issues and trends that we believe may create significant barriers to the widespread adoption of e-learning in the nation's colleges and universities.

\section{Fraud and Cheating Online}

As evidence accumulates about how to make online learning effective, concerns are growing about problems that e-learning poses for students' academic integrity. Academic dishonesty has typically been characterized by the following offenses: "acts of plagiarism, using concealed notes to cheat on tests, exchanging work with other students, buying essays or, in some extreme and notorious cases, asking others to sit examinations for you. ${ }^{\prime 47}$ Research has long documented the widespread prevalence of such forms of dishonesty in postsecondary institutions.

In 1964, for example, Bill Bowers published the first large-scale study of self-reported cheating in postsecondary institutions. ${ }^{48}$ In a sample of more than 5,000 students from ninety-nine U.S. colleges and universities, he found that three-quarters of the students had engaged in at least one dishonest academic behavior. During the 1993-94 academic year, Donald McCabe and Linda Trevino surveyed approximately 1,800 students at nine of the schools that had participated in Bowers's original study. ${ }^{49}$ They found that although the share of students who cheated had increased only slightly, from 63 percent 
in 1963 to 70 percent in 1993, cheaters from the 1993 group engaged in a wider variety of cheating, cheated more often, and engaged in more forms of exam cheating. The share of students admitting to collaborating on individual assignments jumped from 11 percent in 1963 to 49 percent in 1993.

More recently, studies have begun specifically to examine academic dishonesty in online learning environments. In 2006, Mark Lanier surveyed 1,262 students at a large, state-funded university and found that self-reported cheating was more prevalent in online classes than in traditional lecture courses. ${ }^{50}$ In 2000 Kristen Kennedy and several colleagues found that both students and administrators believe it is easier to cheat in distance learning classes. ${ }^{51}$ Kenneth Chapman and several colleagues conducted a survey of 824 business students, both undergraduate and graduate, and found that approximately 75 percent admitted to cheating at some point in their courses. ${ }^{52}$ Among those who had taken an e-learning course, 24 percent admitted to having cheated on a web-based examination. More strikingly, 42 percent indicated that they would cheat on electronic exams if given the opportunity. A recent report by the Government Accountability Office (GAO) also reported a set of alarming findings pertaining to faculty and administrative toleration of academic dishonesty in online courses at for-profit institutions. ${ }^{53}$

Many institutions are exploring ways to address cheating in online courses, including having students take exams on campus or in testing centers or replacing high-stakes testing with assessments, such as longer-term projects, that are seen as less susceptible to cheating. ${ }^{54}$ Perhaps more important, colleges must ensure that institutional policies regarding academic dishonesty and course grading standards are followed strictly to create a culture of academic integrity in the online environment. The work of Donald McCabe, Linda Trevino, and Kenneth Butterfield suggests that perceived social norms, attitudes toward cheating, and knowledge of institutional policy regarding cheating will generally predict course conduct from students in online learning environments. ${ }^{55}$

\section{Low-Income and Underprepared Students}

One argument in favor of e-learning is its potential to improve access to higher education among lower-income and academically underprepared students. Online learning, supporters say, makes postsecondary education more affordable, expands geographic access (for example, to rural areas), and provides needed flexibility for students who cannot attend traditional classes because of full-time work and child-care responsibilities. Realizing that potential, however, will not be easy.

Over the past two decades, much public discussion has focused on "digital divides" and their implications for both youth and adults. In an article in the Encyclopedia of Adolescence Linda Jackson describes three generations of such divides, all by income and race. ${ }^{56}$ The first generation was the divide in access to digital technologies, especially the Internet; access increased with income and was higher among whites than African Americans. As public access to the Internet increased in schools, libraries, and other public spaces, a second digital divide emerged, again primarily by income and race, this one based on broadband Internet access. Researchers, educators, and policy makers have argued that broadband access fundamentally changes the way people interact 
with the Internet, including how often they go online, how much time they spend, and what they do. As these gaps have shown signs of narrowing, yet a third digital divide, this one in the intensity and nature of Internet use, has gained attention. Research has shown that among those with access to the Internet, African Americans go online less often than their white peers. A gap is also growing between youth who use the Internet in diverse and engaging ways, such as social networking or searching for information about major life issues (health care, finding a job), and youth who use it as a more narrow and less engaging resource, such as seeking entertainment online through music or video clips. These types of divides too tend to be structured along racial and ethnic and socioeconomic backgrounds.

The digital divides, particularly the thirdgeneration divide, can lead to differences not only in users' cognitive, social, and psychological development but also in their technology skills and confidence. And because lack of confidence is one of the most frequently cited barriers to adult Internet use, these digital divides may, ironically, decrease enrollment in e-learning among the very groups for whom e-learning is supposed to expand postsecondary access. The divides may also raise dropout rates among students who enroll in e-learning. Online courses, in fact, often have significantly higher dropout rates than face-to-face courses. ${ }^{57}$ One primary reason students give for dropping out is technical problems-problems that students without access to broadband Internet may be especially likely to experience. ${ }^{58}$ And students who lack technology skills and confidence may be less likely to persist when such problems arise. Thus, if e-learning is to increase access to college among low-income students and specific racial and ethnic groups, institutions will have to address digital divides in terms not only of students' access to technology but also of their technology skills and literacy.

Online courses, in fact, often have significantly higher dropout rates than face-toface courses. One primary reason students give for dropping out is technical problems-problems that students without access to broadband Internet may be especially likely to experience.

Underprepared students too may face barriers to success in e-learning courses. Figlio, Rush, and Yin, for example, found, in the study already noted, that students with low grade-point averages who enrolled in the e-learning section of a microeconomics class scored significantly lower on course exams than did those in the live instruction section. ${ }^{59}$ Research examining underprepared students, though limited, has typically reached a similar conclusion: academically underprepared students often perform worse than their peers in online courses. The finding is not surprising in light of the importance of self-regulatory skills in learning generally. And given that e-learning often shifts to the learner more control over important learning decisions, such as what and how much to study, self-regulatory skills such as selfmonitoring and self-evaluation become even stronger predictors of student motivation, 
achievement, and course completion. One way to improve the skills of underprepared students is to build instructional supports into e-learning courses to help students selfregulate and make effective use of the control they are given over their learning. ${ }^{60}$ Several interventions that prompt self-regulation through reflective questions also show promise for supporting critical learning processes during e-learning, though more work is needed to evaluate the specific effectiveness of these interventions among academically underprepared students. ${ }^{61}$ Educators' increasing interest in learning analytics also holds promise for overcoming the barriers faced by these students. Data collected from large populations of online learners can provide insight into the usage and performance of different types of learners and help curriculum planners design courses that meet the specific needs of underprepared students. ${ }^{62}$

\section{Cost Issues}

Although one of the most common reasons given by academic leaders at postsecondary institutions for developing online courses and programs is to generate new revenue streams and potentially to lower the costs of providing a postsecondary education, the cost-effectiveness of e-learning remains largely an open question. Lawrence Bacow and his coauthors report that relatively few institutions believe e-learning reduces their costs, and, in fact, most believe that online courses are at least as expensive to provide as traditional courses. ${ }^{63}$ This perspective is based largely on the significant start-up costs of e-learning, including investments in technology, course design, and the training of instructors, but also on recurring costs, such as those that result from increased coordination demands and technical support. These costs can be a significant barrier to entry for institutions seeking to adopt e-learning instruction. Indeed, Babson
Survey Research Group estimates that a small subset of postsecondary institutions currently educate the majority of online students and predicts that future growth will come largely from those same institutions rather than from new institutions. ${ }^{64}$

Nevertheless, some analysts believe that e-learning can reduce the cost of education. Bowen and his coauthors, for example, ran several cost simulations to try to estimate how much the institutions in their study could save by shifting to hybrid learning. ${ }^{65}$ Although the simulations are speculative and the results vary depending on the assumptions that are adopted, they show that hybrid learning may promise significant savings in total instructor compensation costs. In higher education today, far more e-learning courses are led by instructors rather than by machines, thus limiting the extent to which institutions can realize these cost savings. But future adoption of more interactive, machineguided courses could significantly lower costs. ${ }^{66}$ Tamara Battaglino, Matt Halderman, and Eleanor Laurans stress that the important question is not simply whether e-learning is cheaper but whether it can achieve similar or better learning outcomes at a lower cost. ${ }^{67}$

\section{Other Unanswered Questions}

Several other important questions will require the attention of educators, administrators, and policy makers as postsecondary e-learning continues to expand. One such question concerns the impact of e-learning on more distal measures of student achievement, such as retention and the transfer of learning, both to other courses and to the workplace. Most e-learning studies assess student achievement during the course itself or immediately upon completion. When these studies assess retention at all, they usually do so within a month of when students finish 
the course.$^{68}$ In addition, they often assess achievement based on students' cognitive knowledge and attitudes, at the expense of other important learning outcomes, such as how they apply what they are learning. Admittedly, the failure to assess achievement using longer-term measures is not confined to research on e-learning; much of the adult learning research focuses on shorter-term, cognitive outcomes. Yet it is not possible to grasp fully the implications of e-learning in postsecondary settings without examining how it affects students' ability to retain and apply what they have learned.

As colleges increasingly seek to make their e-learning courses available to an international audience, it will also be important to conduct research that spans different countries and cultures. Much of the research in this area has been conducted using college students in the United States, which raises questions about whether findings will translate across national and cultural boundaries. For instance, students' attitudes toward and acceptance of e-learning may vary depending on their cultural norms, beliefs, and values. In addition, research has found that cultural differences in technology use and digital divides that have been largely addressed in the United States continue to persist in other parts of the world, such as rural China. ${ }^{69}$ In other parts of the world, it may also be important to shift attention from how e-learning compares to classroom learning to how e-learning can provide postsecondary educational opportunities that otherwise do not exist.

\section{Conclusion}

The use of e-learning in postsecondary education has expanded rapidly over the past decade, and all indicators suggest that growth will continue in the years to come. E-learning has also attracted intensive research interest, with thousands of studies over the past several decades examining its effectiveness. Although the dominant paradigm in this area-comparing e-learning with classroom instruction-has long been faulted, research is only now beginning to move away from the "does it work" question toward a greater focus on understanding the role of different instructional features and supports in determining the effectiveness of e-learning. Future research should use rigorous experimental designs to examine how e-learning programs that vary in terms of content, interactivity, and other important instructional features affect students' ability to acquire different types of knowledge and skills. Yet advances in e-learning design must also be coupled with efforts to eliminate current barriers to the widespread adoption of online instruction. Academics and institutions need to collaborate to address the challenges surrounding academic integrity in online environments, devise effective support systems for underprepared learners, evaluate the economic models that underlie e-learning, and understand how to deliver e-learning across geographic and cultural boundaries. 


\section{Endnotes}

1. I. Elaine Allen and Jeff Seaman, Going the Distance: Online Education in the United States, 2011, report prepared for the Babson Survey Research Group (Wellesley, Mass.: Babson Survey Research Group, November 2011).

2. Lawrence S. Bacow and others, Barriers to Adoption of Online Learning Systems in U.S. Higher Education, report prepared for Ithaka S+R (New York: Ithaka S+R, May 2012).

3. Allen and Seaman, Going the Distance (see note 1).

4. Paul Taylor and others, The Digital Revolution and Higher Education: College Presidents, Public Differ on Value of Online Learning, report prepared for Pew Social \& Demographic Trends (Washington: Pew Research Center, August 2011).

5. Kenneth G. Brown, Steven D. Charlier, and Abigail Pierotti, "E-learning at Work: Contributions of Past Research and Suggestions for the Future," in International Review of Industrial and Organizational Psychology, vol. 27, edited by Gerard P. Hodgkinson and J. Kevin Ford (Chichester, U.K.: Wiley, 2012), pp. 89-114.

6. William G. Bowen and others, Interactive Learning Online at Public Universities: Evidence from Randomized Trials, report prepared for Ithaca S+R (New York: Ithaca S+R, May 2012), p. 7.

7. Brown, Charlier, and Pierotti, "e-Learning at Work" (see note 5), p. 93.

8. Allen and Seaman, Going the Distance (see note 1).

9. University of Phoenix, 2011 Academic Annual Report (cdn.assets-phoenix.net/content/dam/altcloud/doc/ about_uopx/academic-annual-report-2011.pdf [July, 30, 2012]).

10. Kaplan University, Academic Report: The Year in Review, 2009-2010 (Chicago: Kaplan Higher Education Corporation, 2011).

11. David J. Deming, Claudia Goldin, and Lawrence F. Katz, "For-Profit Colleges," Future of Children 23, no. 1 (2013).

12. Alexandria Walton Radford, Learning at a Distance: Undergraduate Enrollment in Distance Education Courses and Degree Programs, report prepared for the National Center for Education Statistics (U.S. Department of Education, October 2011).

13. Allen and Seaman, Going the Distance (see note 1).

14. Taylor and others, The Digital Revolution and Higher Education (see note 4).

15. Instructional Technology Council, Trends in E-learning: Tracking the Impact of E-learning at Community Colleges (Washington: Instructional Technology Council, March 2012).

16. "Online Learning by the Numbers," Chronicle of Higher Education, November 5, 2010, pp. B28-B29.

17. Allen and Seaman, Going the Distance (see note 1).

18. Richard E. Clark, "Reconsidering Research on Learning from Media," Review of Educational Research 53 (1983): 445-49; Richard E. Clark, "Media Will Never Influence Learning," Educational Technology Research and Development 42, no. 2 (1994): 21-29.

19. Richard E. Clark and others, "An Analysis of the Failure of Electronic Media and Discovery-Based Learning: Evidence for the Performance Benefits of Guided Training Methods," in Handbook of Training and Improving Workplace Performance, volume 1: Instructional Design and Training Delivery, edited by Kenneth H. Silber and Wellesley R. Foshay (New York: John Wiley and Sons, 2009), p. 264. 
20. Steven M. Ross, Gary R. Morrison, and Deborah L. Lowther, "Educational Technology Research Past and Present: Balancing Rigor and Relevance to Impact School Learning," Contemporary Educational Technology 1, no. 1 (2010): 19.

21. Elaine K. Bailey and Morton Cotlar, "Teaching Via the Internet," Communication Education 43 (1994): 184-93; Starr Roxanne Hiltz and Barry Wellman, "Asynchronous Learning Networks as a Virtual Classroom," Communications of the ACM 40 (1997): 44-49; Robert B. Kozma, "Will Media Influence Learning? Reframing the Debate," Educational Technology Research and Development 42, no. 2 (1994): 7-19; Shu-Sheng Liaw, "Designing the Hypermedia-Based Learning Environment," International Journal of Instructional Media 28 (2001): 43-46; Patrick Sullivan, "Gender Differences and the Online Classroom: Male and Female College Students Evaluate Their Experiences," Community College Journal of Research and Practice 25 (2001): 805-18.

22. Bowen and others, Interactive Learning Online at Public Universities (see note 6), p. 7.

23. Taylor and others, The Digital Revolution and Higher Education (see note 4).

24. Bacow and others, Barriers to Adoption of Online Learning Systems in U.S. Higher Education (see note 2).

25. Robert M. Bernard and others, "How Does Distance Education Compare with Classroom Instruction? A Meta-Analysis of the Empirical Literature," Review of Educational Research 74 (2004): 379-80.

26. William G. Bowen and Kelly A. Lack, Current Status of Research on Online Learning in Postsecondary Education, report prepared for Ithaka S+R (New York: Ithaka S+R, May 2012).

27. Mark W. Lipsey and David B. Wilson, "The Efficacy of Psychological, Educational, and Behavioral Treatment," American Psychologist 48 (1993): 1181-209.

28. Clark, "Media Will Never Influence Learning” (see note 18).

29. Bradford S. Bell and Steve W. J. Kozlowski, "Active Learning: Effects of Core Training Design Elements on Self-Regulatory Processes, Learning, and Adaptability,” Journal of Applied Psychology 93 (2008): 296-316.

30. Bernard and others, "How Does Distance Education Compare with Classroom Instruction?" (see note 25), pp. $379-439$.

31. Ibid.

32. Traci Sitzmann and others, "The Comparative Effectiveness of Web-Based and Classroom Instruction: A Meta-Analysis," Personnel Psychology 59 (2006): 623-64. The authors define web-based instruction on pp. 623-24.

33. Barbara Means and others, Evaluation of Evidence-Based Practices in Online Learning: A Meta-Analysis and Review of Online Learning Studies, report prepared for the U.S. Department of Education, Office of Planning, Evaluation, and Policy Development (Washington: U.S. Department of Education, September 2010).

34. Traci Sitzmann, "A Meta-Analytic Examination of the Instructional Effectiveness of Computer-Based Simulation Games," Personnel Psychology 64 (2011): 489-528.

35. David N. Figlio, Mark Rush, and Lu Yin, "Is It Live or Is It Internet? Experimental Estimates of the Effects of Online Instruction on Student Learning.” Working Paper 16089 (Cambridge, Mass.: National Bureau of Economic Research, June 2010).

36. Bowen and others, Interactive Learning Online at Public Universities (see note 6).

37. Terry Anderson, "Getting the Mix Right Again: An Updated and Theoretical Rationale for Interaction," International Review of Research in Open and Distance Learning 4, no. 2 (2003): 3. 
38. Brown, Charlier, and Pierotti, “E-learning at Work” (see note 5), p. 108.

39. Steve W. J. Kozlowski and Bradford S. Bell, “A Theory-Based Approach for Designing Distributed Learning Systems," in Toward a Science of Distributed Learning, edited by Stephen M. Fiore and Eduardo Salas (Washington: APA, 2007), pp. 15-39.

40. Jennifer J. Vogel and others, "Computer Gaming and Interactive Simulations for Learning: A MetaAnalysis," Journal of Educational Computing Research 34 (2006): 229-43.

41. Michael G. Moore, "Three Types of Interaction," American Journal of Distance Education 3, no. 2 (1989): $1-6$.

42. Anderson, "Getting the Mix Right Again," (see note 37).

43. Richard E. Mayer, "Elements of a Science of e-Learning," Journal of Educational Computing Research 29 (2003): 297-313.

44. Robert M. Bernard and others, “A Meta-Analysis of Three Types of Interaction Treatments in Distance Education," Review of Educational Research 79 (2009): 1243-89.

45. Winfred Arthur Jr. and others, "Effectiveness of Training in Organizations: A Meta-Analysis of Design and Evaluation Features," Journal of Applied Psychology 88 (2003): 234-45.

46. Bacow and others, Barriers to Adoption of Online Learning Systems in U.S. Higher Education (see note 2).

47. Jean Underwood and Attila Szabo, "Academic Offences and E-learning: Individual Propensities in Cheating,” British Journal of Educational Technology 34 (2003): 468.

48. William J. Bowers, Student Dishonesty and Its Control in College (New York: Columbia University, Bureau of Applied Social Research, 1964).

49. Donald L. McCabe and Linda K. Trevino, "Individual and Contextual Influences on Academic Dishonesty: A Multicampus Investigation,” Research in Higher Education 38 (1997): 379-96.

50. Mark M. Lanier, “Academic Integrity and Distance Learning,” Journal of Criminal Justice Education 17 (2006): 244-61.

51. Kristen Kennedy and others, "Academic Dishonesty and Distance Learning: Student and Faculty Views," College Student Journal 34 (2000): 309-15.

52. Kenneth J. Chapman and others, “Academic Integrity in the Business School Environment: I'll Get by with a Little Help from My Friends,” Journal of Marketing Education 26 (2004): 236-49.

53. Government Accountability Office, For-Profit Schools: Experiences of Undercover Students Enrolled in Online Classes at Selected Colleges (GAO-12-1250), report prepared for the Chairman, Committee on Health, Education, Labor, and Pensions, U.S. Senate (GAO, October 2011).

54. Bacow and others, Barriers to Adoption of Online Learning Systems in U.S. Higher Education (see note 2).

55. Donald L. McCabe, Linda K. Trevino, and Kenneth D. Butterfield, "Cheating in Academic Institutions: A Decade of Research," Ethics and Behavior 3 (2001): 219-32.

56. Linda A. Jackson, “Digital Divides,” in Encyclopedia of Adolescence, edited by Roger J. R. Levesque (New York: Springer, 2011), pp. 701-14.

57. Instructional Technology Council, Trends in E-learning (see note 15).

58. Carol A. Zavarella, “Computer-Based Instruction and Remedial Mathematics: A Study of Student Retention at a Florida Community College” (PhD diss., University of South Florida, 2008). 
59. Figlio, Rush, and Yin, "Is It Live or Is It Internet?" (see note 35).

60. Shanna Smith Jaggars and Thomas Bailey, Effectiveness of Fully Online Courses for College Students: Response to a Department of Education Meta-Analysis, report prepared for the Community College Research Center (New York: Teachers College, Columbia University, July 2010).

61. Traci Sitzmann and others, "A Multilevel Analysis of the Effect of Prompting Self-Regulation in Technology-Delivered Instruction,” Personnel Psychology 62 (2009): 697-734.

62. Bacow and others, Barriers to Adoption of Online Learning Systems in U.S. Higher Education (see note 2).

63. Ibid.

64. I. Elaine Allen and Jeff Seaman, Class Difference $\$$ : Online Education in the United States, 2010, report prepared for the Babson Survey Research Group (Wellesley, Mass.: Babson Survey Research Group, November 2010).

65. Bowen and others, Interactive Learning Online at Public Universities (see note 6).

66. Bacow and others, Barriers to Adoption of Online Learning Systems in U.S. Higher Education (see note 2).

67. Tamara Butler Battaglino, Matt Halderman, and Eleanor Laurans, "The Costs of Online Learning," in Education Reform for the Digital Era, edited by Chester E. Finn Jr. and Daniela R. Fairchild (Washington: Thomas B. Fordham Institute, 2012), pp. 55-76.

68. Sitzmann, “A Meta-Analytic Examination of the Instructional Effectiveness of Computer-Based Simulation Games" (see note 34).

69. Caroline Haythornthwaite, "Digital Divide and E-Learning," in The Sage Handbook of E-Learning Research, edited by Richard Andrews and Caroline Haythornthwaite (Thousand Oaks, Calif.: Sage, 2007), pp. 97-118. 